ممارسات الريفيات في مجال الملابس والمفروشات وعلاقتها بدرجة الإصابة بين

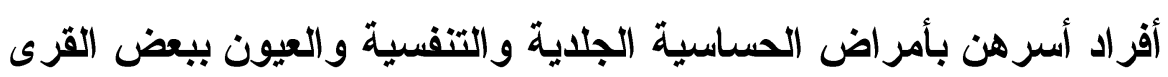
بمحافظة الإسكندرية

آمال السيد العسال و إيمان عوض سراج الدين

المرأة الريفية - فرع معهُ بحوث الارشاد الزراعى والتندية الريفية - الاسكندرية

|المستخص

أجريت الدراسة للأهداف الثالية : - تحديد معارف المبحوثات

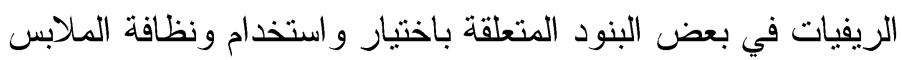

و المفروشات ـ - تحديد ممارسات المبحوثات الريفيات في بعض البنات البنود البنات

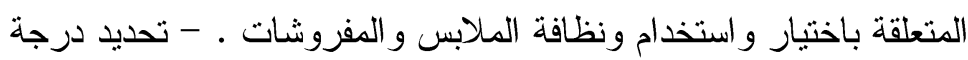

الإصابة بين أفراد الأسر المبحوثة بأمر اض الحساسية الجلدية والتنفسية

و العيون . - تحديد العلاقة بين درجة ممارسات المبحوثات ودرجة الإصابة

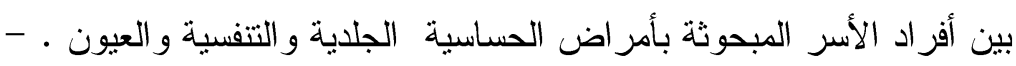

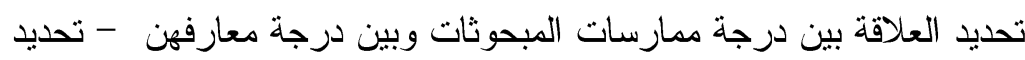

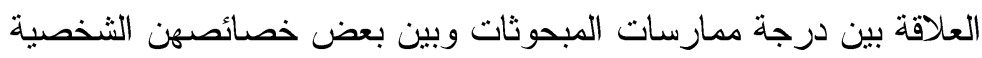

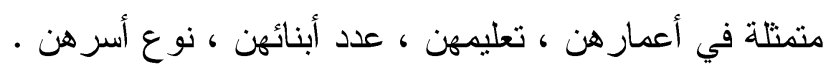

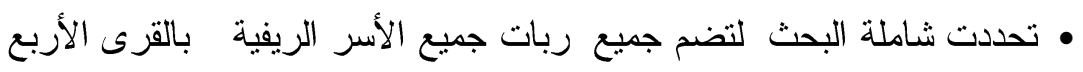
المختارة من منطقة المعمورة الزراعية بمحافظة الإسكندرية ، وتم أخذ عينة بطريقة عشو ائية لتمثل 9.1 \% من تلك الثاملة فبلغ حجمها 150 سيدة ريفية من ربات الأسر ، تم جمع البيانات بالمقابلة الثخصية للمبحوثات باستخدام

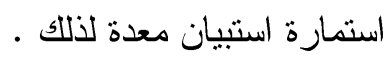

• تم معالجة البيانات إحصائيا باستخدام النسب المئوية و التكرارات في وصف النف النيان

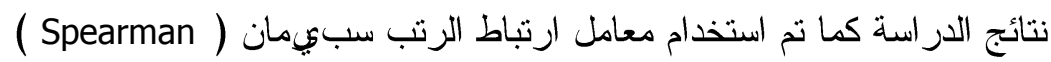

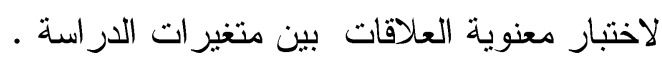

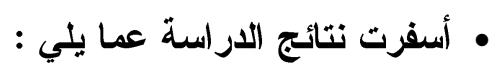

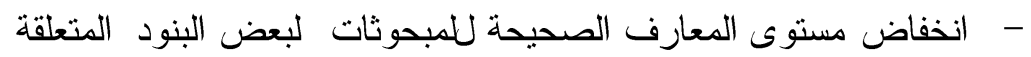
لبختيار واستخدام و العناية بالملابس و الدفروشات لدى 41.3 \% منهن ، بينما

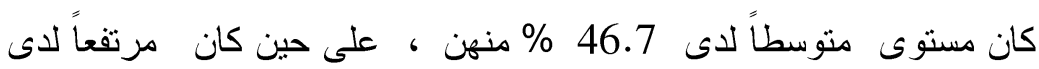
. 12.0 فقط منهن 
- - انخفاض مستوى اتباع المبحوثات الممارسات السليمة لبعض البنود المتعلقة لبختيار و استخدام و العناية بالملابس و المفروشات لدى 94.7 \% منهن ، وبينما كان مستوى متوسطاً لدى 4.0 \% منهن ، ومرتفعاً لدى 1.3 \% فقط من المبحوثات 0

- 49.3 \% من أسر المبحوثات يوجد بين أفر ادها إصابة بلُمر اض الحكة

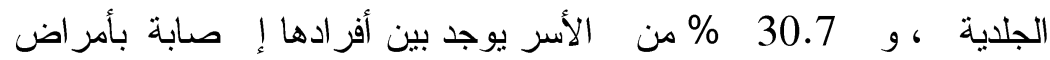
الحساسية التنفسية ( سواء بالأنف أو الصدر ) ) ،و 14.7 \% من الأسر بينهم

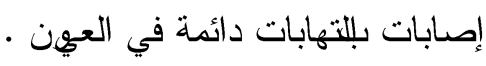
- وجود علاقة ارتباطيه عكسية معنوية عند مستوى معنوية 0.01 بين مجموع عدد الممارسات السليمة التي تتبعها المبحوثات لبعض البنود المتعلقة البهاته لبختيار و استخدام العناية بال ملابس و المفروشات كمتغير مستقل و المتغيرات

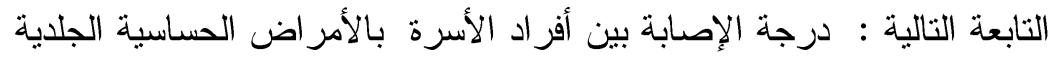

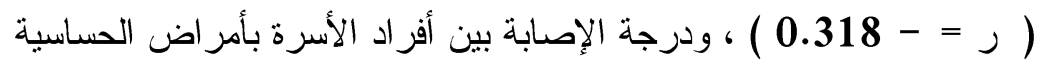
التنفسية ( ر = - 0.246 ) ، ودرجة الإصابة بين أفراد الأسرة بالتهابات

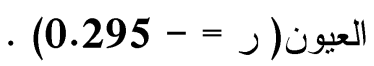

- وجود علاقة ارتباطيه موجبة معنوية عند مستوى معنوية 0.01 بين مجموع المعارف السليمة للمبحوثات لبعض البنود المتعلقة بلختيار و استخدام

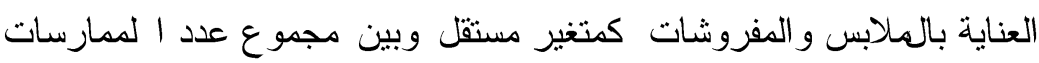

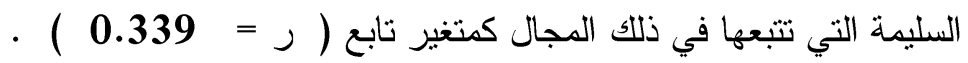

\section{المقدمة و المشكلة البحثية}

تعتبر المنتجات النسيجية سو اء الملابس أو المفروشات أحد الحاجات الأساسية للأفراد في جميع

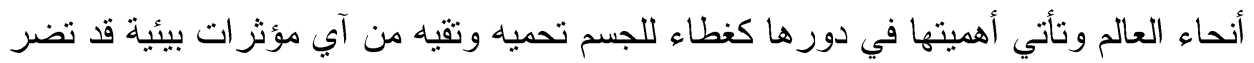

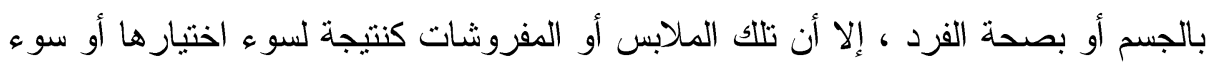

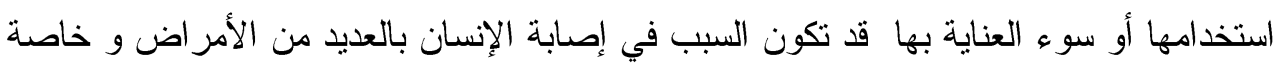

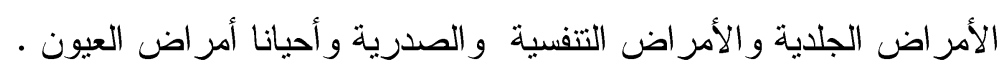

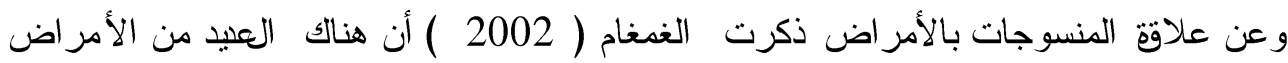

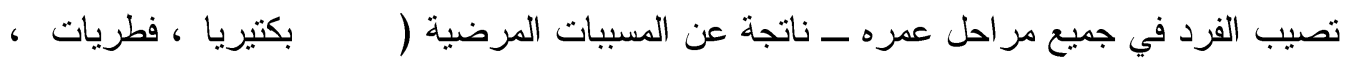

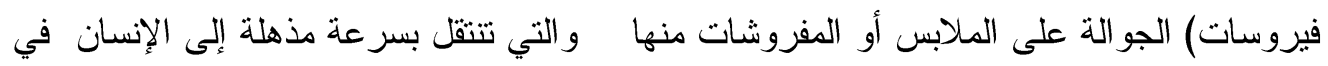

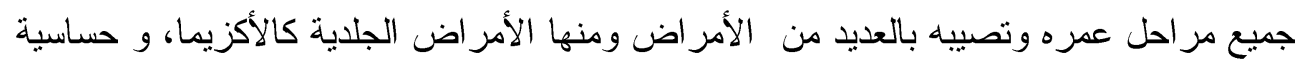

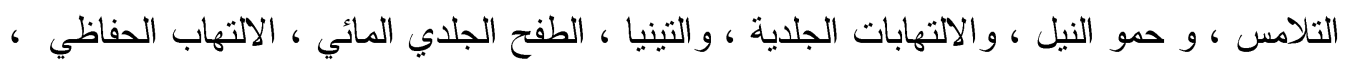

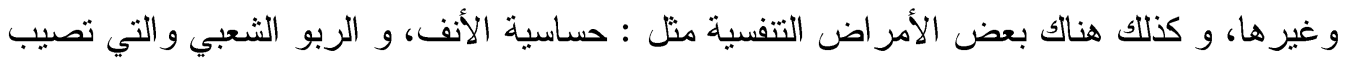


الإنسان بسبب ارتداء أو استخدام بعض الأنواع من المنسوجات التي يدخل في تصنيعها مادة

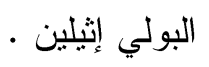

وبينت دراسة لطفي ( 1987 ) أن الاكزيما وحساسية التلامس و الجرب و الالتهابات الجلدية

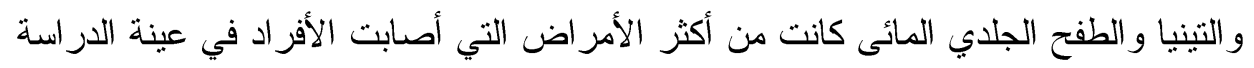

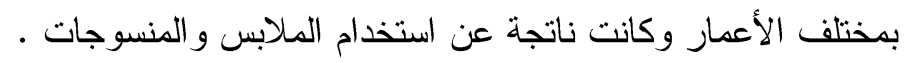
و أظهر Leslie و آخرون ( 1990 ) في در استهم الميدانية أن تلادس الجلد للملابس و المنسوجات من الصوف و البولي استر و النايلون أدي إلى ظهور بعض الأمر اض الجلدية وبعض مشاكل الجهاز التنفسي بالإضافة إلى بعض مشاكل العيون . و أكدت دراسة سالم ( 2002 ) أن 75 \% من أفر اد العينة المصابين بأمر اض الحساسية الجلدية ترجع إصابتهم إلى استخدامهم الألياف الصناعية وصبغاتها ، و 11 \% 11 \% منهم ترجع إصابتهم إلى لى الصبغة في المنتجات الطبيعية ، وأن 14 \% منهم نرجع إصابتهم إلى المنظفات و المطهرات

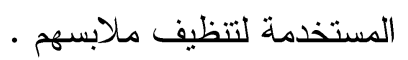

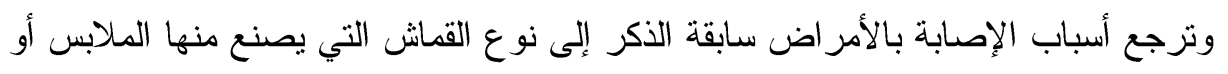

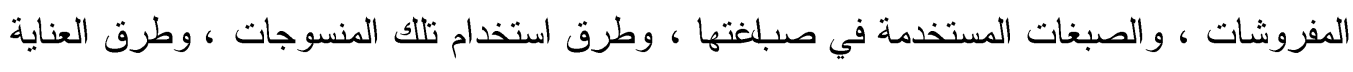

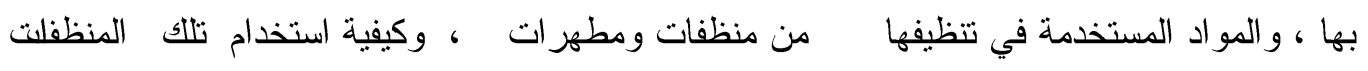

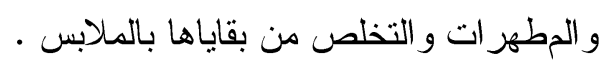

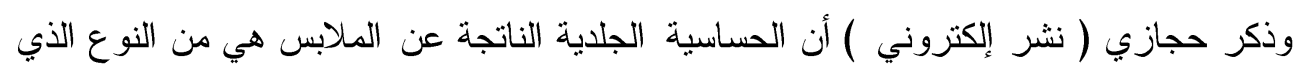

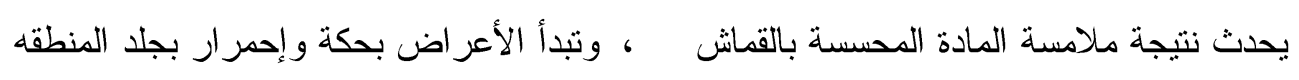

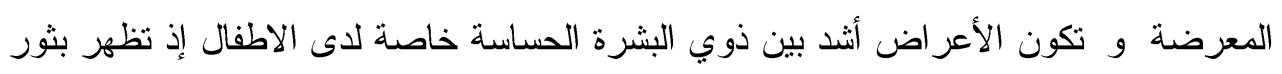

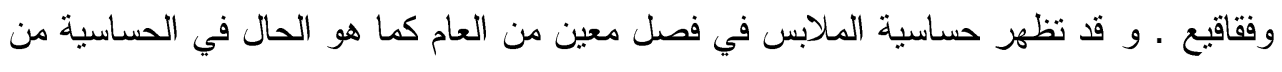

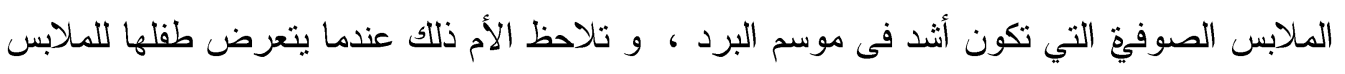

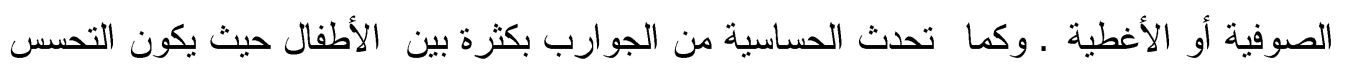

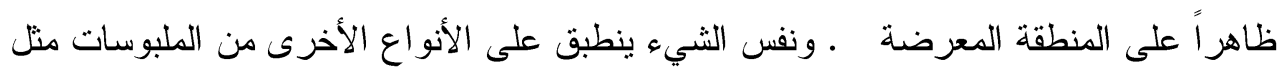
السراويل و أكد كل من حجازي ( نشر إلكتروني ) ، العرادي ( 2004 ) أن نوع القماش الملامس للجسم

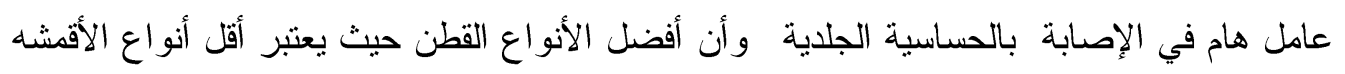

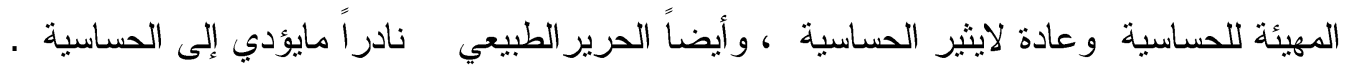
أما الصوف يعتبر عامل مهم في إثارة الحساسية ، وكذلك الألياف الصناعية مثل البوليستر و النايلون

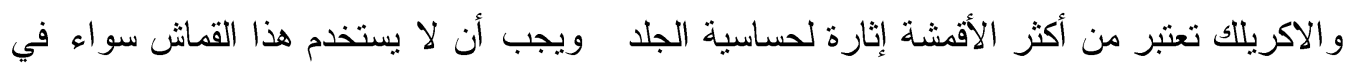

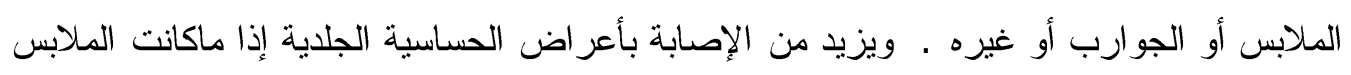

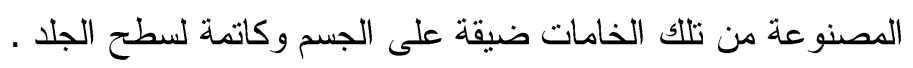


وأضاف العرادي ( 2004 ) أن الملبوسات المصنوعة من الألياف المختلطة ( طبيعية وصناعية ) و هي الأكثر رواجا في العالم ونتشل خليط القطن و البوليستر أو القطن و النايلون قد تسبب

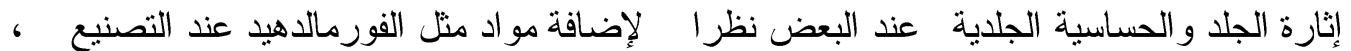
وأوضح أن الإصابة الناتجة عن الملابس و الأقشة تكون عادة على شكل احمرار وحكة شديدة وأحيانا بثور في مناطق الثنايا في الجسم أي مناطق إفراز العرق ، و و يساعد العرق على زيادة

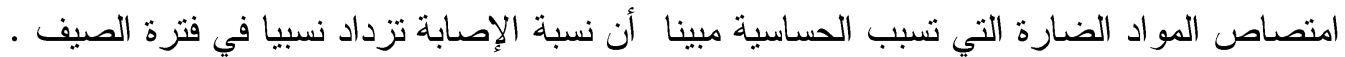
وقال أن لبس الملابس الضيقة ذات الأقمشة المختلطة قد تساهم في الحكة والحساسية في الجلد

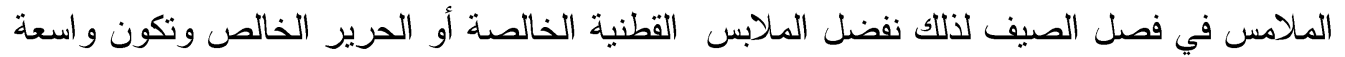
نوعا ما وبعيدة عن تلامس الجلد ، وكما بهضضل لبس الأقطان تحت الملابس ذات الأقشة المختلطة

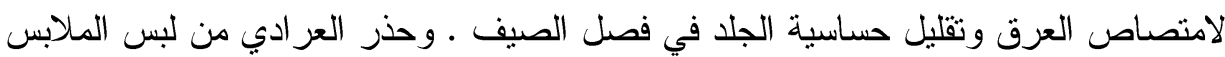
اللاصقة أو الضيقة سو اء في فصل الصيف أو الثتاء و خاصة التي تكون مصنوعة من البوليستر الخالص أو المختلط بمو اد أخرى حيث أنه بللتصاق الجلد تماما بهذه الملابس بحدث ضعف وله التهوية

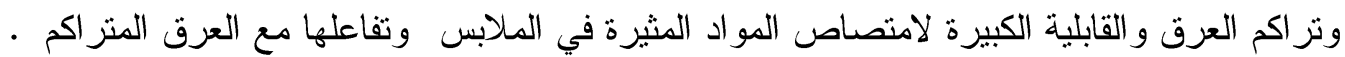

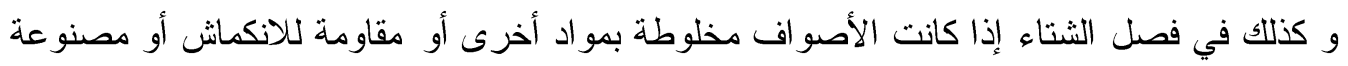

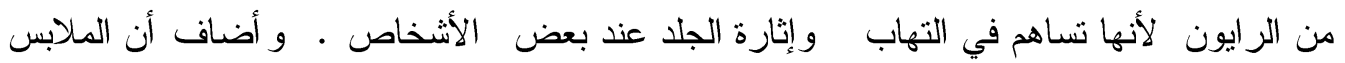

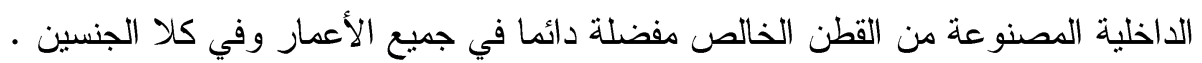

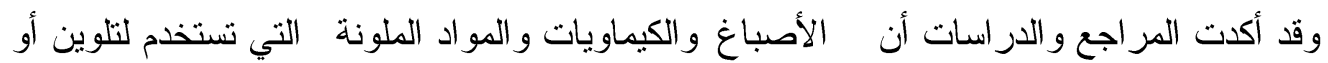

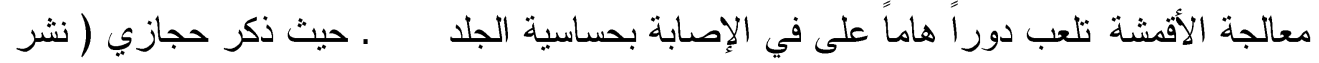

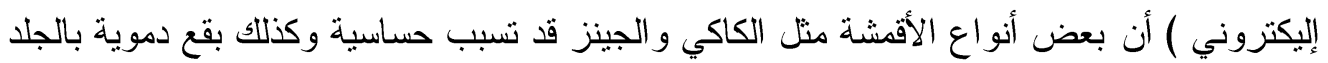
، وذلك قد بكون بسبب الاصباغ أو من المواد الكيماوية المستعملة أثناء تجهيز تلك الأقمشة ، و و يظهر الطفح الجلدي عادة على مناطق السطح الداخلي للفخذين أو الأذرع وينتشر بعد ذلك إلى مناطق وأكدا ال Edwin \& Joe ( 2001 ) أن الأقمشة المصنوعة من الألياف الطبيعية كالقطن و الكتان و الحرير لا تسبب الحساسية الجلدية نتسجة لتلامسها للجسم ، و إنما تتسبب الحساسية من الصبغات الصنات الصناه

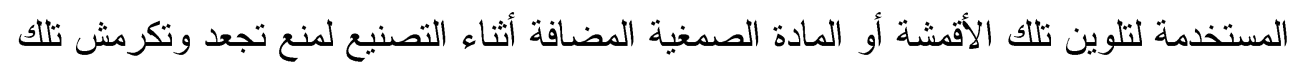

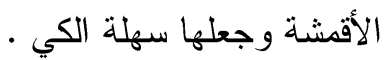

و أثبتت العديد من الدراسات أن الصبغات التي تستخدم حالياً في صباغة الملابس تعتبر من أهم

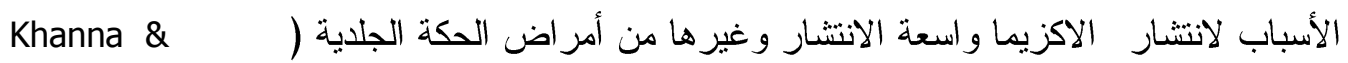
( Sasseville 2001, Lazarov et al 2002, Wd 2012 و أكد Morris ( 2012 ) أن معظم أمر اض الحكة الجلدية تحدث نتيجة احتكاك الجلد بمو اد مثبرة أو مهيجة و أهمها الصبغات أو بقايا المنظفات الصناعية خاصة في الملابس الداخلية التي تلامس الجلد حيث تؤدي إلى إذابة للطبقة الدهنية الحامية للجلد مما يثير ويهيج الجلد ويحدث احمرار وحكة 
و أثنارت لطفي ( 2002 ) إلى ضرورة العناية و الدقة في إضافة المطهرات للغسيل بالكمية المطلوبة وبشكل آمن حتى يقتل أو يقلل من العد الكلي للبكتيريا في المفروشات المنزلية وبنات وبالتالي يحد

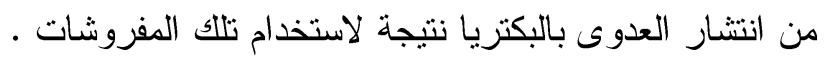

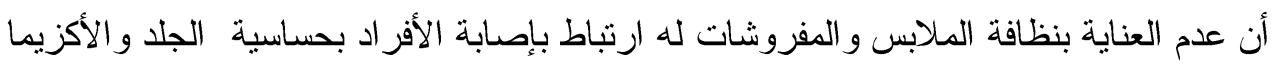
وكذلك حساسية الأنف وحساسية الصدر ( الربو ) وذلك نتيجة لوجود الكائنات الحية الصغيرة التي لئي

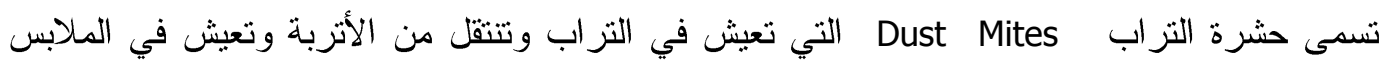

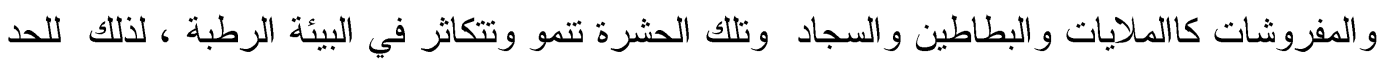

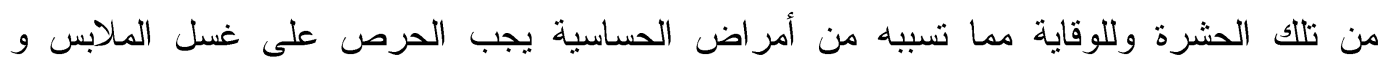

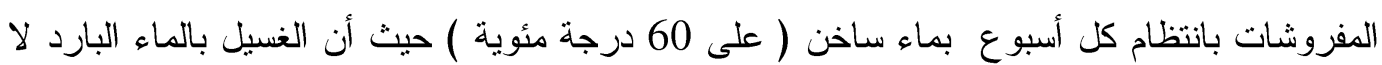

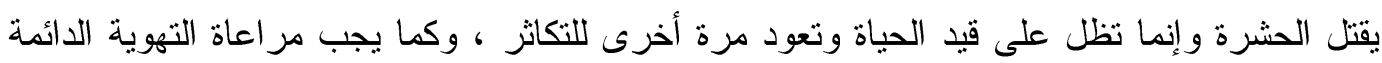

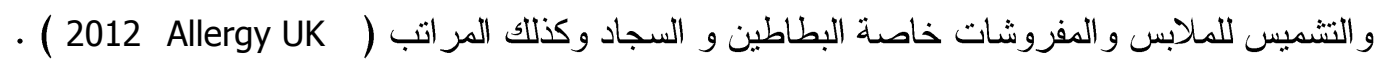

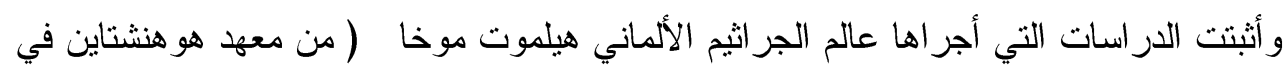

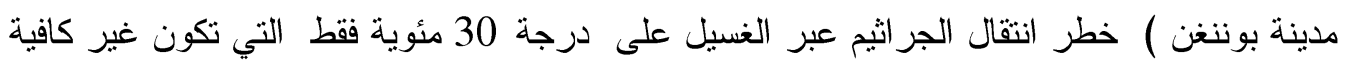

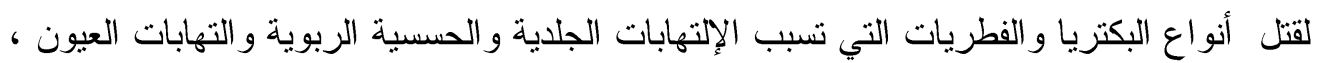
و تبين من الأبحاث أن معظم البكتيريا والفطريات تختفي من الملابس المغسولة بدرجة 60 مئوية ، ويمكن لهذه البكتيريا أن تتجمع في المياه القليلة التي تتبقى في الغسالة الإلكترونية بعد انتهاء الغسيل، وأن تشكل الخطر القادم لدفعة الغسيل القادمة ، وتكثر البكتبريا العضوية عادة في حفاضات الأطفال

وملابسهم الداخلية ، وفي المناثف المستخدمة في تجفيف اليدين و الصحون في المطابخ بينما تكثر

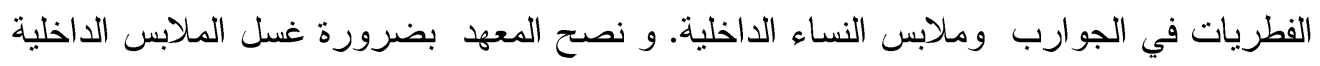

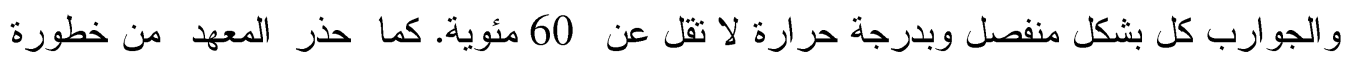

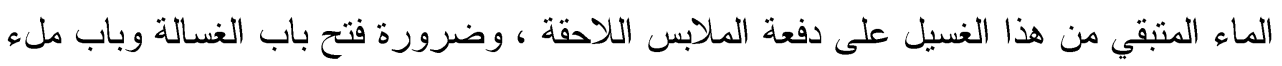

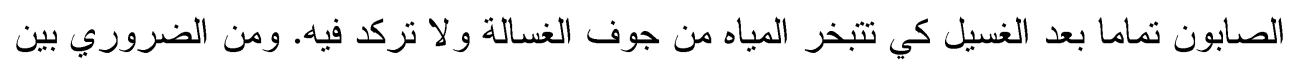

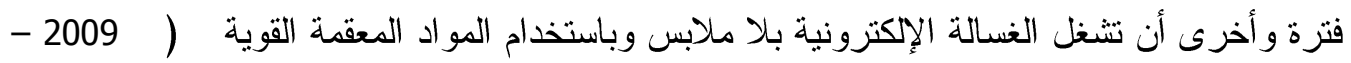
• ( H H Saudi Research and Marketing إلا أنه يجب مر اعاة عدم زيادة كمية المنظفات أو المطهر ات المستخدمة ، أثناء غسلها و الثطف

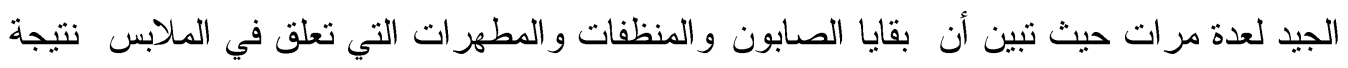

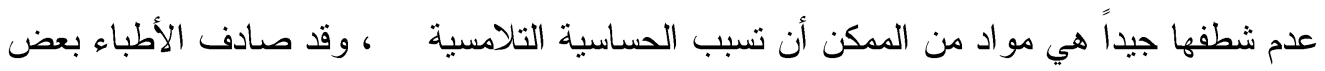

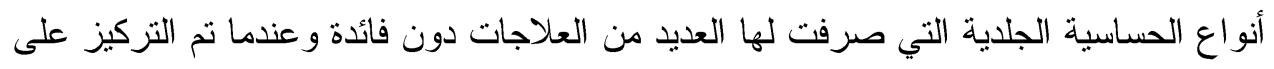
الثطف الجيد للملابس ومر اعاة التخلص تماماً من بقايا المنظفات ولا سيما في الملابس الداخلية

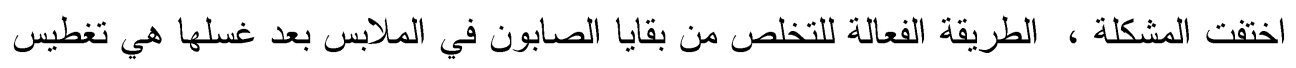
الألبسة بعد شطفها في وعاء ماء مضاف إليه بضع نقط الليمون أو الخل الأبيض، ويتزك لعدة بلهن

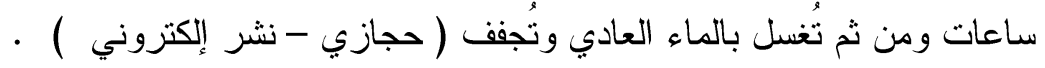


ونظر أ لما أوضحته الدراسات من علاقة أنو اع المنسوجات المستخدمة وطرق معاملتها بالصبغات و الكيماويات بما تسببه من أضرار صحية للمستهلك تتمثل في العديد من أمر اض الحساسية الجلدية

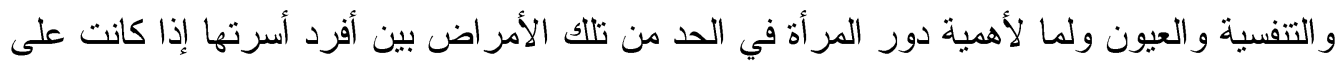

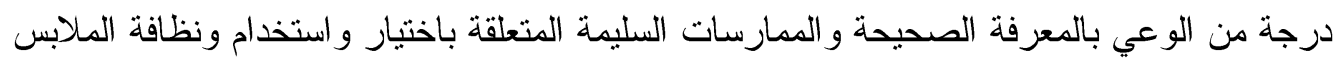
و المفروشات ، ومن ثم تم إجر اء الدر اسة للتعرف على معارف وممارسات المبحوثات الريفيات فيما بلهي

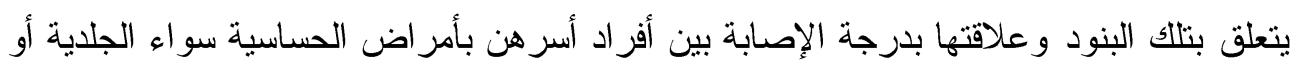

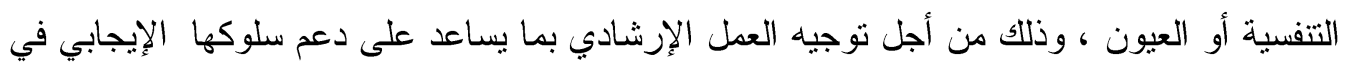

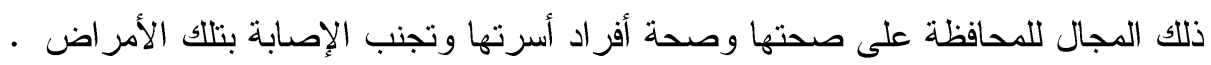

\section{أهداف البحث}

1- تحديد معارف المبحوثات الريفيات في بعض البنود المتعلقة باختيار واستخدام ونظافة الملابس

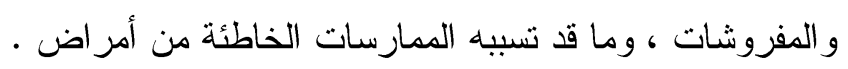

2- تحديد ممارسات المبحوثات الريفيات في بعض البنود المنعلقة باختيار و استخدام ونظافة الملابس و المفروشات .

3- تحديد درجة الإصابة بين أفر اد الأسر المبحوثة بأمر اض الحساسية الجلدية والتنفسية والعيون .

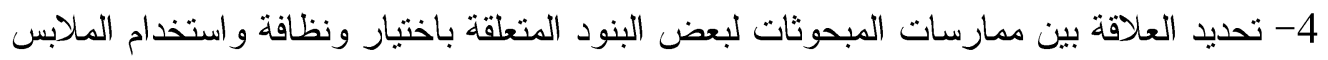
و المفروشات وبين درجة الإصابة بين أفراد الأسر المبحوثة بأمر اض الحساسية الجلدية و التتفسية و العيون .

5- تحديد العلاقة بين ممارسات المبحوثات المتعلقة باختيار ونظافة و استخدام الملابس و المفروشات

$$
\text { وبين معارفهن في نفس المجال }
$$

6- تحديد العلاقة بين ممارسات المبحوثات المتعلقة باختيار ونظافة واستخدام الملابس و المفروشات

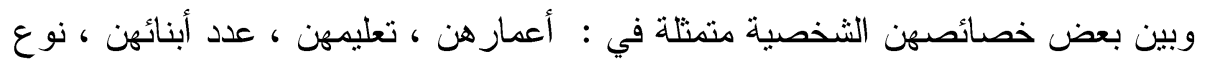
أسر هن وبن بعضن

\section{فروض البحث}

لتحقيق الهدف الرابع والخامس والسادس من الدراسة تم اختبار الفروض البحثية التالية بعد

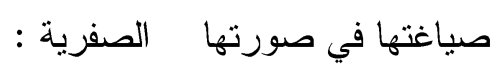

1 - لا توجد علاقة معنوية بين ممارسات المبحوثات المتعلقة باختيار و استخدام ونظافة الملابس

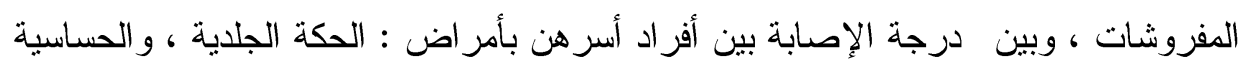

$$
\text { التنفسية ، و التهابات العيون. }
$$

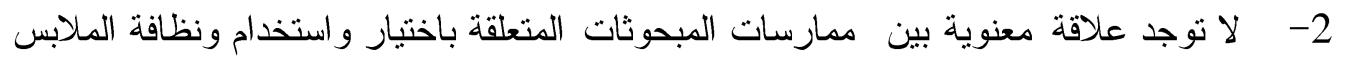

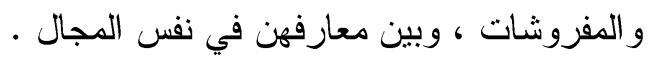


3- لا توجد علاقة معنوية بين ممارسات المبحوثات المتعلقة باختيار واستخدام ونظافة الملابس

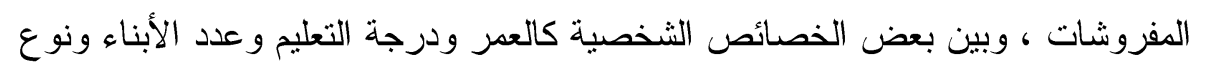
الأسرة.

\section{الطريقة البحثية}

أولاً : اختيار منطقة البحث وتعديد الثاملة والعينة :

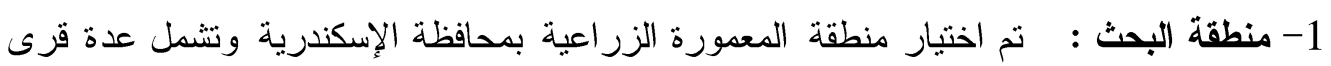

(مثال : سيكلام و أسكوت و الثامي و البرنس البحري و البرنس القبلي ومنشية الأوقاف و والمنشية

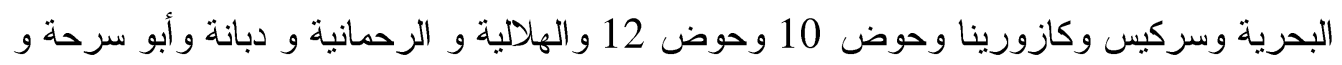

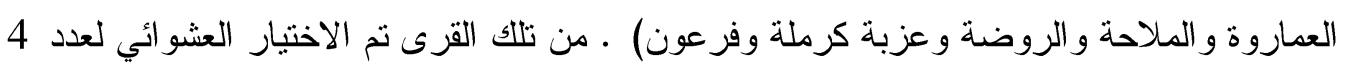

قرى وهي : قرية حوض 10 ، وقرية البرنس البحري ، وقرية البرنس القبلي ، وقرية دبانة .

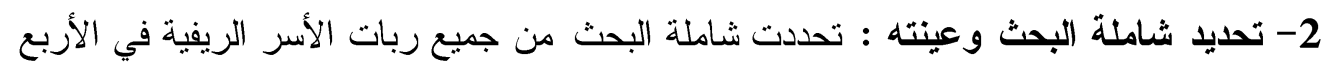

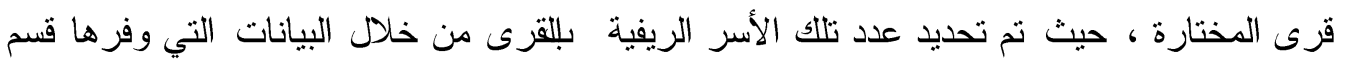
تتمية القرية بمجلس مدينة المنتزه بحي المنتزه ، ووفقاً لتلك البيانات كانت عدد الأسر الريفية بتلك لكن القرى الأربع يبلغ 1643 أسرة .

- نم أخذ عينة عشو ائية غير منتظمة قدرها 150 سيدة ريفية من ربات الأسر لتصن 9.1 \% من الثاملة .

ثانياً: : أسلوب جمع البيانات :

تم جمع البيانات بالمقابلة الثخصية للمبحوثات ربات اتبات الأسر الريفية المختارة ، وذلك باستخدام استمارة استبيان شملت بنودها 1 - بعض الخصائت بالئس الثخصية والأسرية للمبحوثة : كعمرها

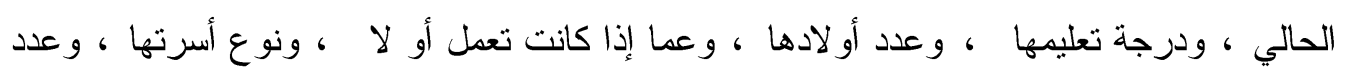

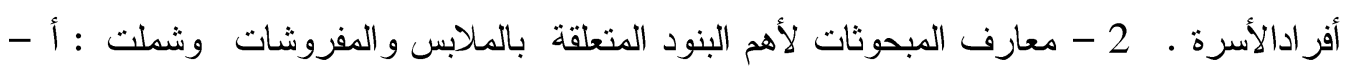

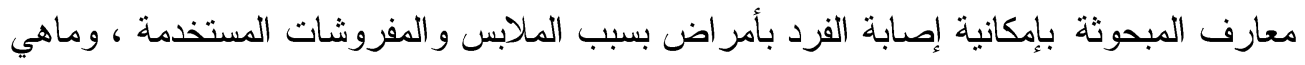

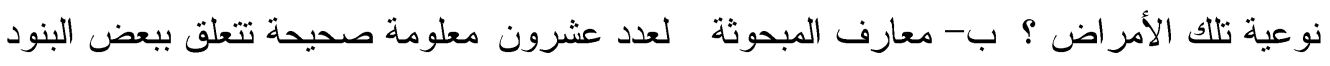

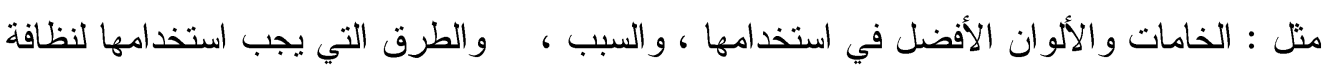

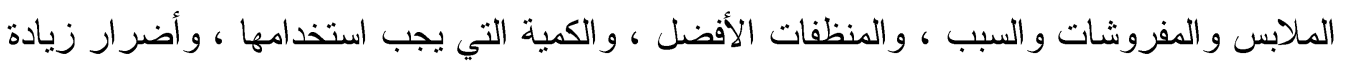

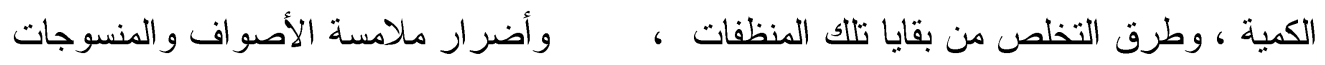
الصناعية للجلد أو غطاء الوجه للتدفئة في الثتاء . 3- مجاء مارسات المبحوثات لأهم البنود المتعلقة

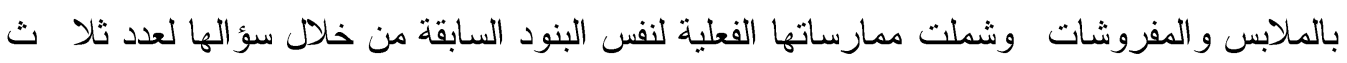

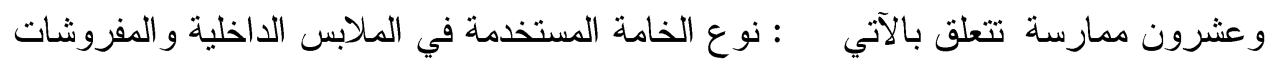

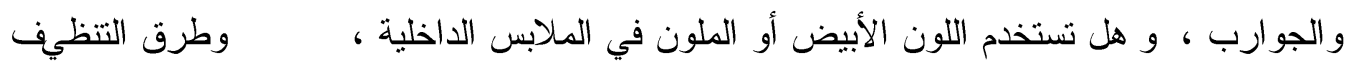

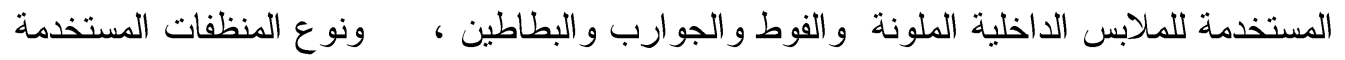

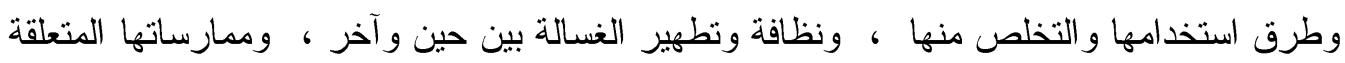


تبلاصق الملابس الصوفية والصناعية للجسم مباشرة ، وممارسة الغطاء بالبطانية على الوجه مباشرة

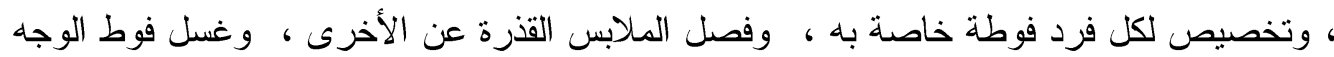

بمفردها قبل الغسيل ... 4- كما شملت استمارة الإستبيان التعرف على درجة إصابة المبحوثة أو أحد أفر اد أسرتها لبعض الأمر اض الجلدية و التتفسية و التهابات العيون . ثالثاً : قياس متغيرات الار استة : 1

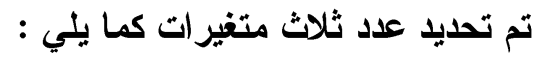

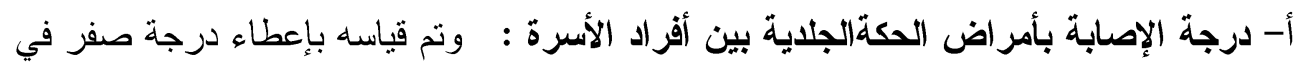

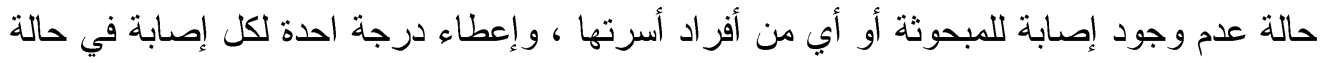

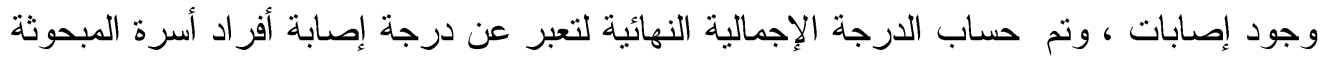

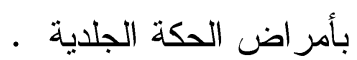
ب- درجة الإصابة بأمراض الحساسية التنفسية بين أفراد الأسرة : ونم قياسه كالمتغير السابق .

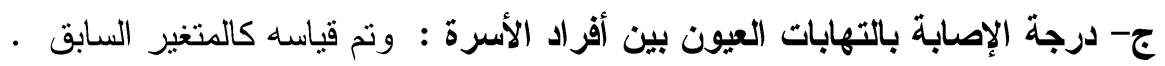

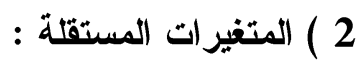

أ- الارجة الكلية المتعلقة بالممارسات الصحيحة التي تتبعها المبحوثات فيما يتعلق باختيار

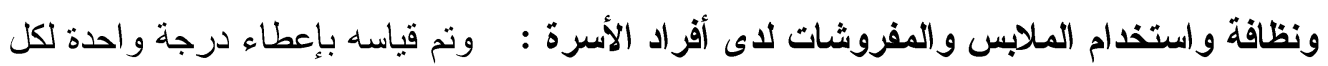

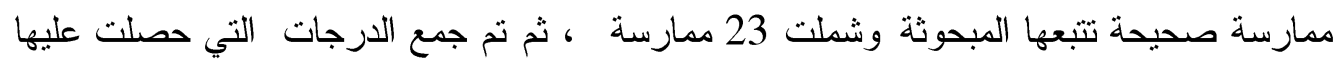
المبحوثة لإجمالي عدد 23 ممارسة لتمثل الدرجة الكلية المتعلقة لبلممارسات الصحيحة التي تتبعها

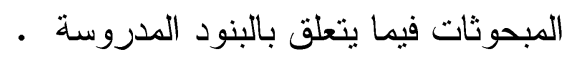
( ملحوظة : تم استخدام هذا المتغير كمتغير مستقل مع المتغيرات التابعة سابقة الذكر المتعلقة بدرجة الإصابة بالأمر اض ، وكما تم استخدامه كمتغير تابع مع المتغيرات المستقلة التالية ) . ب- الارجة الكلية لمجموع المعارف الصحيحة للمبحوثات و المتعلقة باختيار واستخدام و ونظافة

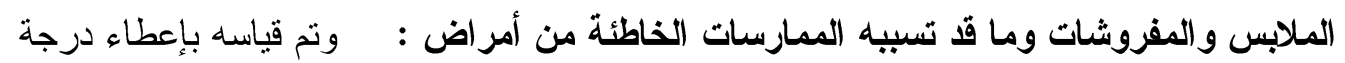

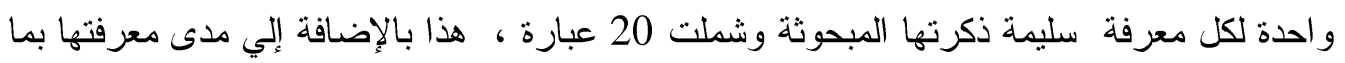

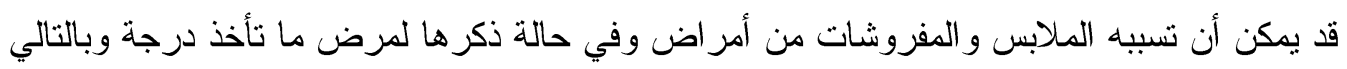

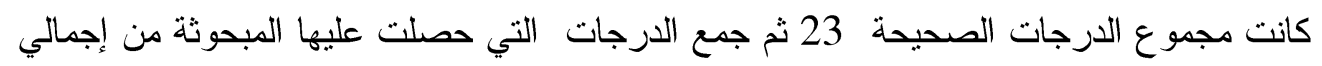
عدد 23 لتمثل الدرجة الكلية لمجموع عدد المعارف الصحيحة المبحوثات . ج- بعض المتغيرات الثخصية و الأسرية :

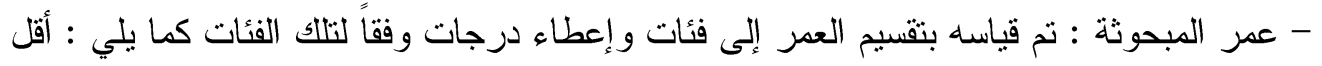

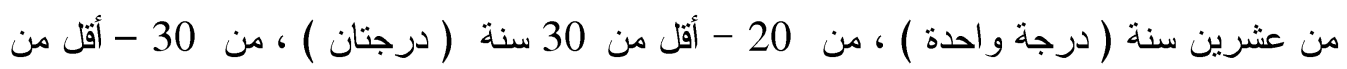

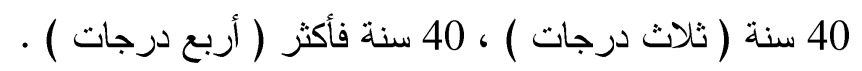

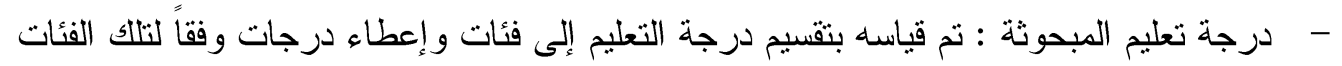
كما يلي : لا ثقر أو لا تكتب ( صفر ) ، تقرأ وتكتب ولكنها لم تتم المرحلة الإبتدائية أعطيت (درجة 
واحدة) ، أتتى المرحلة الإبتدائية ( درجتان) ، حاصلة على الإعدادية ( ثلاث درجات ) ، الثانوي

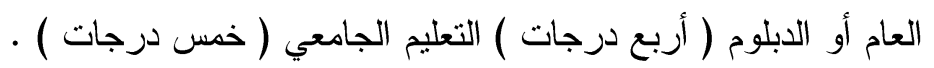
- عدد أبناء المبحوثة : وضع الرقم الدال على عدد الأبناء .

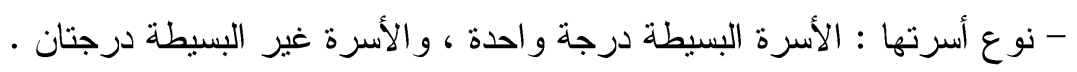

\section{النتائج البحثية}

أولاً : بعض الخصائص الثخصية والأسرية للمبحوثات :

أثنارت نتائج البحث ( جدول 1 ) إلى بعض الخصائص الثخصية والأسرية للمبحوثات كما يلي :

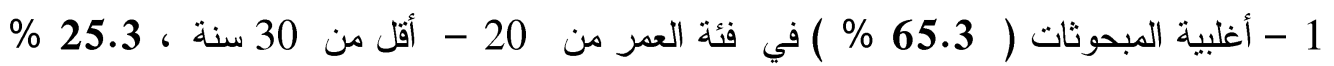
منهن في فئة العمر من 30 - أقل من 40 سنة ـ بينما 8 \% منهن أقل من 20 سنة ، 1.3 \% فقط أكبر من 40 سنة . من فئس

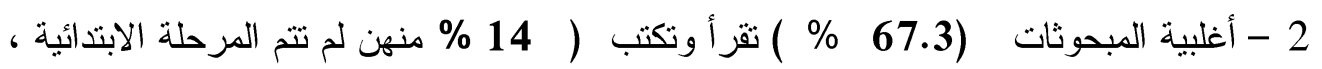
18.7 \% أتمت المرحلة الابتدائية ، و 16 \% حصلن على الإعدادية ، 20.0 \% \% منهن حصلن على دبلوم ، 5.3 \% منهن أتممن التعليم الجامعي .

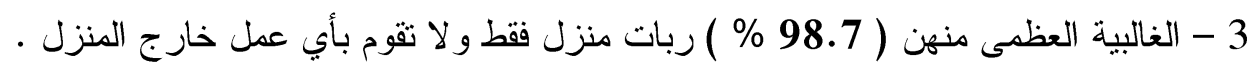

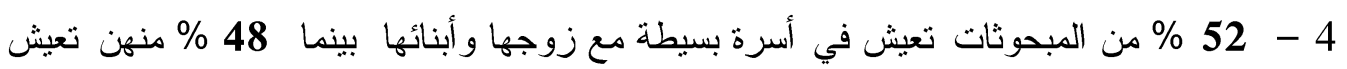

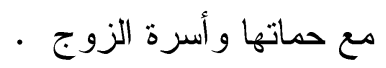
5 - عدد الأبناء لدى 49.3 \% منهن أقل من 3 أبناء ، 30.7 \% منهن لديهن 3 - 4 أبناء ، 5.3 \% منهن فقط لدهن 5 أبناء فأكثر 6 - وعن درجة تعليم أبناء المبحوثات 66 \% من المبحوثات لديهن أبناء لا يز الون في المرحلة

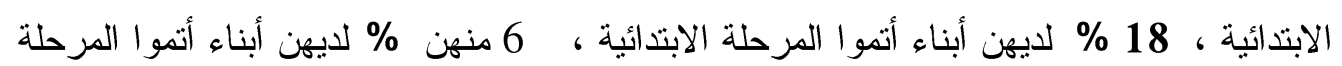

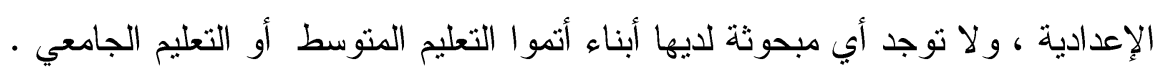




\begin{tabular}{|c|c|c|c|c|c|}
\hline$\%$ & 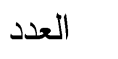 & الخصائص & $\%$ & 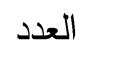 & الخصائص \\
\hline & & عدد الأبناء_ــ & & & عمر المبحوثة \\
\hline 46.0 & 96 & 1-2 فرد & 8.0 & 12 & أقل من 20 سنة \\
\hline 30.7 & 46 & 3 - 4 أفراد & 65.3 & 98 & من 20 - > 30 سنة \\
\hline \multirow[t]{2}{*}{5.3} & 8 & 5 - 6 أفر اد & 25.3 & 38 & من 30 - > 40 سنة \\
\hline & & & 1.3 & 2 & 40 سنة فأكثر \\
\hline & & درجة تعليم الأبناء & & & درجة تعليمها \\
\hline 100 & 150 & دون سن الإلز ام & 32.7 & 49 & لا تقرأ و لا تكتب \\
\hline 66 & 44 & في المرحلة الابتدائية & 67.3 & 101 & تقر أ وتكتب \\
\hline 18 & 12 & إتمام المرحلة & 14.0 & 21 & لم تحصل على الابتدائية \\
\hline \multirow[t]{4}{*}{6} & 4 & الابتدائية & 18.7 & 28 & حاصلة على الابتدائية \\
\hline & & إتمام المرحلة & 16.0 & 24 & حاصلة على الإعدادية \\
\hline & & الإعدادية & 20.0 & 30 & حاصلة على دبلوم \\
\hline & & & 5.3 & 8 & أتمت التعليم الجامعي \\
\hline & & نوع الأسرة & & & العمل \\
\hline 52.0 & 78 & بسيطة & 1.3 & 2 & ت تعمل \\
\hline 48.0 & 72 & غير بسيطة & 98.7 & 148 & لا تعمل \\
\hline
\end{tabular}

ثانيــــــــــاً : معارف المبحوثات ربات الأسر الريفية المتعلقة باختيار واستخدام ونظافة الملابس والمفروشات وما قد تسببه الممارسات الخاطئة من أمر اض :

أظهرت نتائج الدر اسة ( جدول 2 ) معارف المبحوثات فيما يتعلق باختيار واستخدام ونظافة الملابس و المفروشات وما قد تسبيه الممارسات الخاطئة من أمر اض فيما يلي :

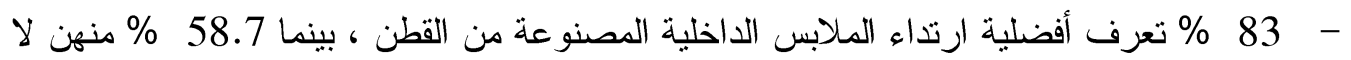
يعرفن السبب لأفضلية الملابس الداخلية القطنية . - 61.3 \% تعرف أفضلية ارتداء الجوارب المصنوعة من خامة القطن ، و و لا تعرف 70.7 \% منهن السبب في أفضلية الجوارب القطنية . - 21.3 \% أجابت أنه هفضضل ارتداء للملابس الداخلية البيضاء عن الملونة ، بينما لا تعرف الغالبية العظمى منهن 93.3 \% السبب في أفضلية ارتداء الملابس الداخلية البيضاء اللون عن 
- 25.3 \% ذكرت أهمية غسل الملابس الداخلية الملونة قبل الاستخدام ، و 20.0 \% ذكرت أهمية نقع الملابس الداخلية الملونة قبل الاستخدام ، ولم تعرف أي مبحوثة أفضل مدة لنقع الملابس

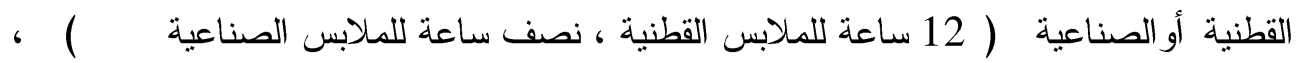
18.7 \% ذكرت خطأ إطالة مدة نقع الملابس ل لهدة يوم كامل 24 ساعة . - لم تبدي أي مبحوثة معرفتها لأفضلية عدم زيادة كمية المسحوق في غسيل الملابس و المنسوجات

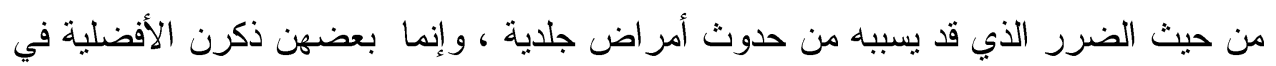
التوفير المادي ، و البعض الآخر ذكرن ما قد يسببه من إتلاف للملابس أو المفروشات 0

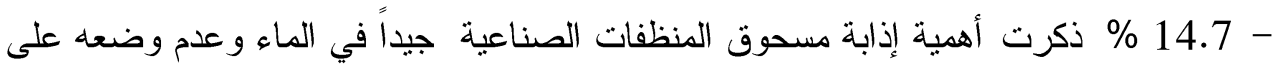

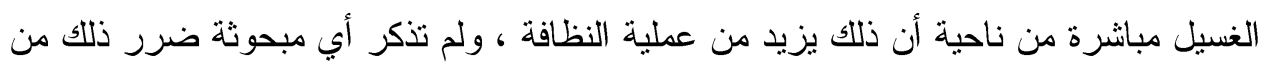

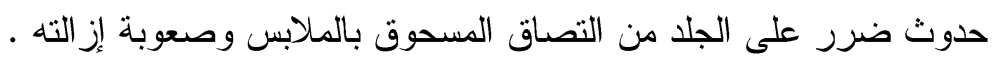

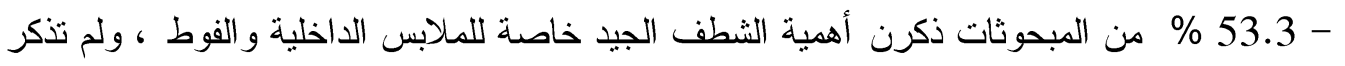

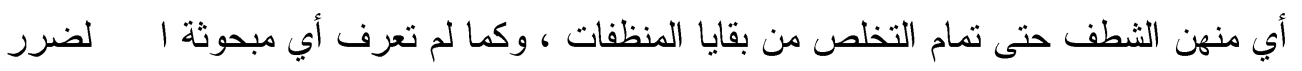

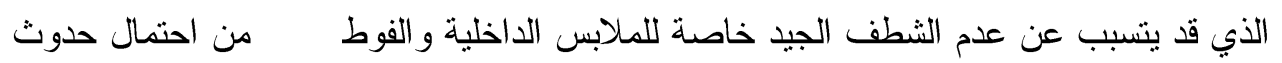

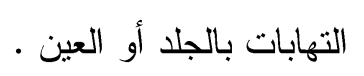

- 74.7 \% من المبحوثات ذكرن أفضلية عدم زيادة الكمية المستخدمة من الكلور في نظافة الملابس أو المفروشات ، ومن حيث معرفتهن ب الضرر من وضع الكلور بكمية كبيرة لنظافة

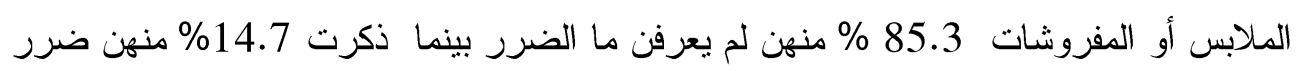
على اليدين أثناء الشطف . - 56.0 \% من المبحوثات ذكرن أفضلية عدم ارتداء الملابس الصوفية ملامسه للجسم مباشرة

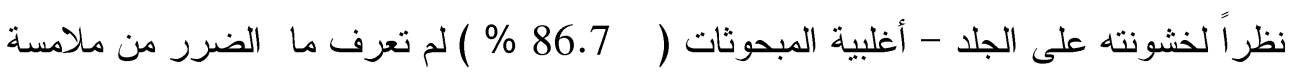
الجسم لفترة طويلة للملابس المصنوعة من الصوف أو الألياف الصناعية .

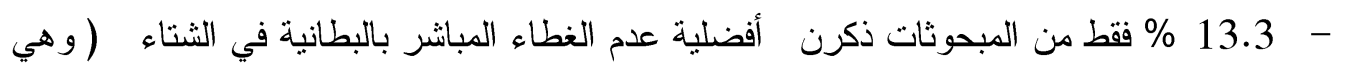

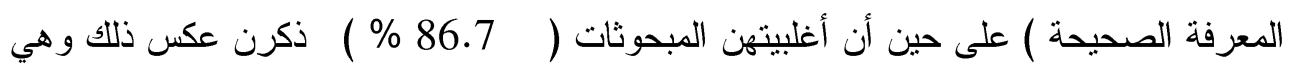
معرفة خاطئة .

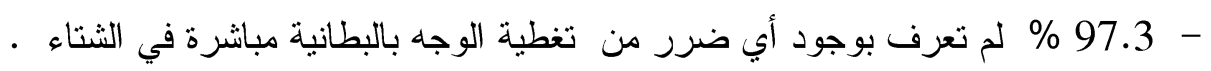

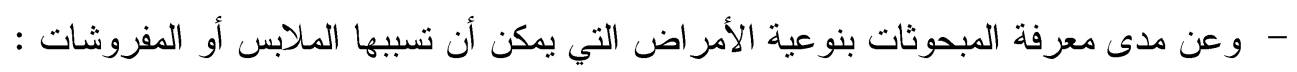

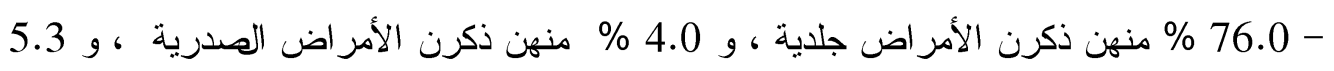

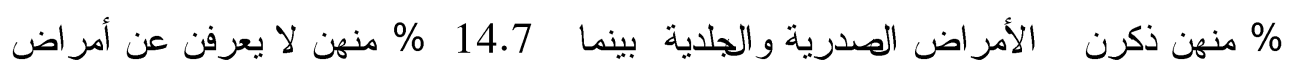

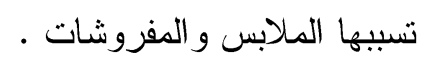


جدول ( 2 ) توزيع المبحوثات وفقاً لمعارفهن المتعلقة باختيار واستخدام ونظافة الملابس

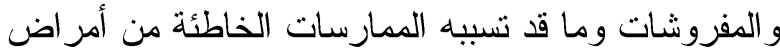

\begin{tabular}{|c|c|c|c|c|}
\hline \multicolumn{2}{|c|}{ لا تعرف } & \multicolumn{2}{|r|}{ تعرف } & \multirow[t]{2}{*}{ المعارف } \\
\hline$\%$ & العدد & $\%$ & العدد & \\
\hline 17.3 & 26 & 83 & 124 & 1- 1 نوع خامة القماش الأفضل للملابس الداخلية \\
\hline 58.7 & 88 & 41.3 & 62 & 2- السبب لأفضلية الملابس الداخلية القطنية ؟ \\
\hline 28.7 & 58 & .3 & 92 & 3- نوع الخامة الأفضل للجوارب \\
\hline 70.7 & 106 & 29.3 & 44 & 4- السبب في أفضلية الجو ارب القطنية ؟ \\
\hline 78.7 & 118 & 21.3 & 32 & 5- اللون الأفضل للملابس الداخلية \\
\hline 93.3 & 140 & 6.7 & 10 & 6- السبب في أفضلية الملابس الداخلية البيضاء اللون عن الملونة ؟ \\
\hline 74.7 & 112 & 25.3 & 38 & 7- أهمية غسل الملابس الداخلية الملونة قبل الاستخدام \\
\hline 80.0 & 120 & 20.0 & 30 & 8- أهمية نقع الملابس الداخلية الملونة قبل الاستخدام \\
\hline 100 & 150 & 0 & 0 & 9- أفضل مدة للنقع للملابس القطنية ، و الصناعبة (12 ساعة ، نصف ساء \\
\hline 81.3 & 122 & 18.7 & 28 & 10 - خطأ إطالة مدة نقع الملابس ليوم كامل 24 ساعة \\
\hline 100 & 150 & 0 & 0 & 11- أفضلية عدم زيادة كمية المسحوق في غسيل الملابس و المنسوجات \\
\hline 85.3 & 128 & 4.7 & 22 & على الغسيل مباشرة أذهية مسحق المنظفات الصناعية جيداً في الماء و عدم وضعه \\
\hline 46.7 & 70 & 53.3 & 80 & 13- أهية الثطف الجيد خاصة للملابس الداخلية و الفوط ؟ \\
\hline 100 & 150 & 0 & 0 & و الفوط ؟ الضرر الذي قد يتسبب عن عدم الثطف الجيد خاصة للملابس الداخلية \\
\hline 25.3 & 38 & 74.7 & 112 & 15- أفضلية عدم زيادة الكمية المستخدمة من الكلور في نظافة الملابس أو \\
\hline 85.3 & 128 & 14.7 & 22 & 16- الضرر من وضع الكلور بكمية كيبرة لنظافة الملابس أو المفروشات ؟ \\
\hline 44.0 & 66 & 56.0 & 84 & 17- أفضلية عدم ارتداء الملابس الصوفية ملامسه للجسم مبانشرة \\
\hline 86.71 & 130 & 13.3 & 20 & الصوف أو الألياف من ملامسة الجسم لفترة طويلة للملابس المصنوعة من \\
\hline 86.71 & 130 & 13.3 & 20 & 19- أفضلية عدم الغطاء البباشر بالبطانية في الثنتاء \\
\hline 97.3 & 146 & 2.7 & 4 & 20- الضرر من تغطية الوجه بالبطانية مباثرة في الثنتاء ؟ \\
\hline 24.0 & 36 & 76.0 & 114 & - 21 - مر اضي الأمر اض التي يمكن أن تسبيها الملابس أو المفروشات ؟ \\
\hline 96.0 & 144 & 4.0 & 6 & - - أمر اض صدرية \\
\hline 94.6 & 142 & 5.3 & 8 & - أمر اض صدرية وجلدية \\
\hline 85.3 & 128 & 14.7 & 22 & ل الاتعرف \\
\hline
\end{tabular}

تشير النتائج ( الجدول 2 ) إلى أن أكثر البنود التي تتخفض فيها درجة معارف المبحوثات :

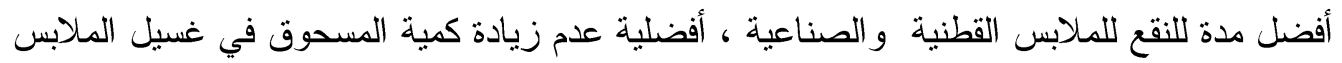
و المنسوجات ، الضرر الذي قد يتسبب عن عدم الثطف الجيد خاصة للملابس الداخلية و الفوط حيث

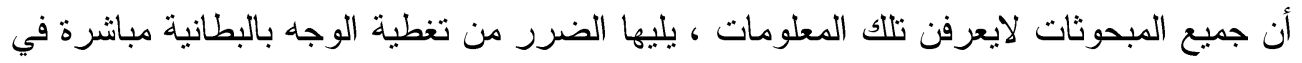
الثتاء حيث لم يذكر ها سوى 2.7 \% منهن فقط ، يليها السبب في أرتداء الملابس الداخلية البيضاء

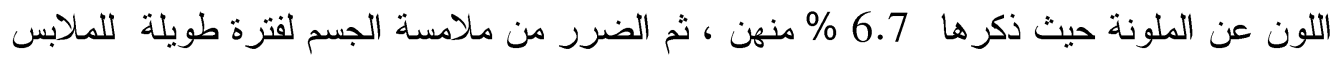
المصنوعة من الصوف أو الألياف الصناعية ، و أفضلية عدم الغطاء المباشر بالبطانية في الثتاء ذكرن تلك المعلومتان 13.3 \% منهن . 
ممارسات المبحوثات ربات الأسر الريفية فيما يتعلق باختيار واستخدام ونظافة ثالث الملابس و المفروشات الخاصة بأفر اد الأسرة :

بينت النتائج البحثية جدول ( 3 ) الممارسات السليمة التي تتبعها المبحوثات ربات الأبرات الأسر الريفية فيما يتعلق باختيار و استخدام ونظافة الملابس و المفروشات فيما يلي :

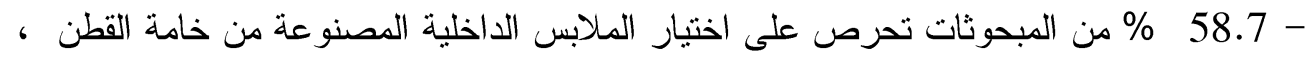

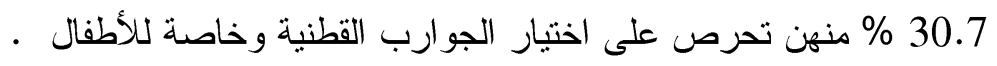

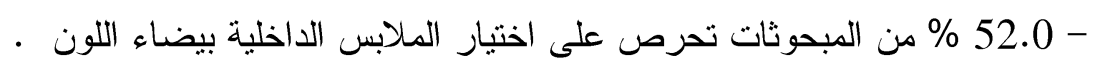
- 40.0 \% من المبحوثات تحرص على نقع الملابس الداخلية الملونة قبل ارتدائها .

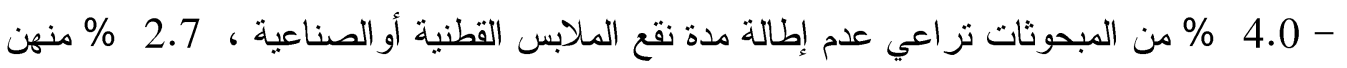

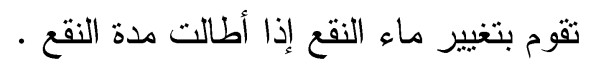

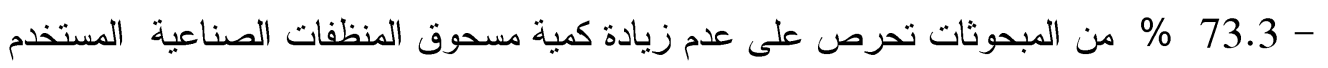
في غسيل الملابس • - 88.0 \% من المبحوثات تراعي إذابة مسحوق المنظفات الصناعية جيداً في الماءو وعدم وضع المسحوق على الملابس مباشرة . - 52.0 \% من المبحوثات تحرص على عدم زيادة الكمية المستخدمة من الكلور في نظافة الملابس أو المفروشات . - 45.3 \% تستخدمن الماء الساخن في غسيل الملابس الداخلية و المفروشات .

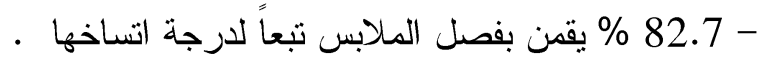

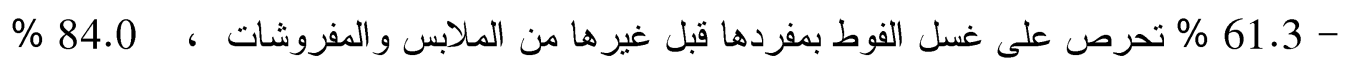

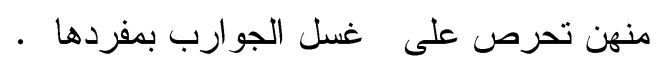
- 60.0 \% من المبحوثات تحرص على شطف الملابس خاصة الداخلية و الفوط مرتين ، ولم تذكر أب مبحوثة حرصها على الثطف حتى تمام التخلص من المنظفات ، وكما لم تذكر أب مبحوثة فئة

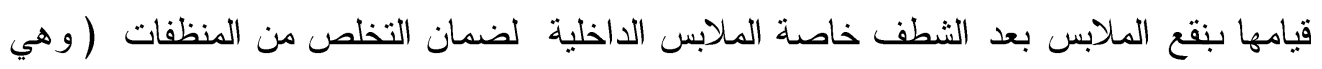

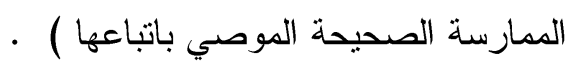
- 54.7 \% من المبحوثات يقمن بغلي الملابس الداخلية بعد غسلها ل

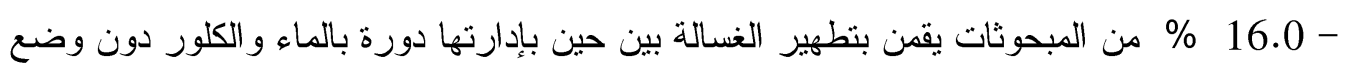
غ غيل

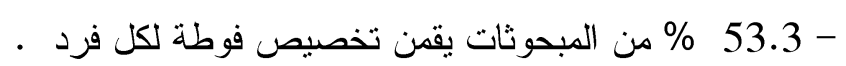

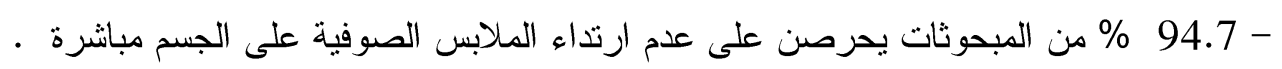

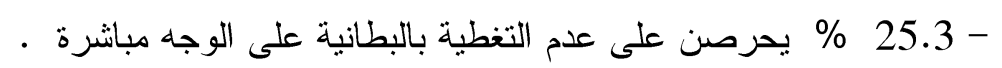

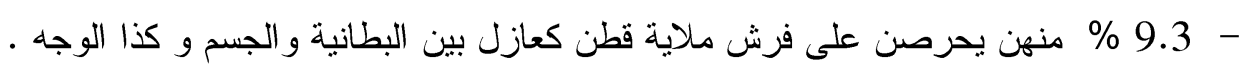

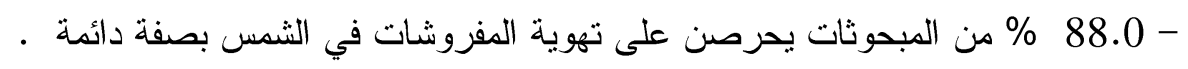
- 100 \% من المبحوثات يقمن بغسل البطاطين مع الثطف و التجفيف الجيد في الثمس قبل فيل فئل

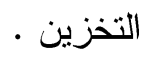


جدول ( 3 ) توزيع المبحوثات وفقاً لبعض ممارساتهن فيما يتعلق باختيار و استخدام ونظافة الملابس و المفروشات الخاصة بأفر اد الأسرة

\begin{tabular}{|c|c|c|c|c|}
\hline \multicolumn{2}{|c|}{ لا لا تمارس } & \multicolumn{2}{|c|}{ 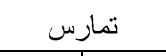 } & \multirow{2}{*}{ الممارسات } \\
\hline$\%$ & العدد & $\%$ & العدد & \\
\hline 41.3 & 62 & 58.7 & 88 & 1- الحرص على اختيار الملابس الداخلية المصنو عة من خامة القطن \\
\hline 69.3 & 104 & 30.7 & 46 & 2- الحرص على اختيار الجوارب القطنية وخاصة للأطفال \\
\hline 48.0 & 72 & 52.0 & 78 & 3- الحرص على اختيار الملابس الداخلية بيضاء اللون \\
\hline 60.0 & 90 & 40.0 & 60 & 4- الحرص على نقع الملابس الداخلية الملونة قبل الاستخدام \\
\hline 96.0 & 144 & 4.0 & 6 & 5- عدم إطالة مدة نقع الملابس القطنية أو الصناعية \\
\hline 97.3 & 146 & 2.7 & 4 & 6- تغيير ماء النقع إذا طالت الددة \\
\hline 26.7 & 40 & 73.3 & 110 & 7- عدم زيادة كمية مسحوق المنظفات الصناعية المستخدم في غسيل الملابس \\
\hline 12.0 & 18 & 88.0 & 132 & 8- 8- إذابة مسحوق المنظفات الصناعية جياً في الماء وعدم وضع المسحوق على الملابس \\
\hline 54.7 & 82 & 45.3 & 68 & 9- استخدام الماء الساخن في غسيل الملابس الداخلية والكفروشات \\
\hline 45.3 & 68 & 54.7 & 82 & 10 - غلي الملابس الداخلية بعد غسلها \\
\hline 17.3 & 26 & 82.7 & 124 & 11- فصل الملابس حسب اتساخها \\
\hline 28.7 & 58 & 61.3 & 92 & 12- غسل الفوط بمفردها قبل الملابس والمفروشات \\
\hline 16.0 & 24 & 84.0 & 126 & 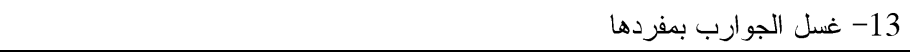 \\
\hline 100 & 150 & 0 & 0 & 14- شطف الملابس خاصة الداخلية و الفوط حتى تمام التخلص من المنظفات \\
\hline 40.0 & 60 & 60.0 & 90 & - شطف الملابس خاصة الداخلية والفوط أكثر من مرة (مرثين ) \\
\hline 100 & 150 & 0 & 0 & 15- نقع بعد الثطف خاصة الملابس الداخلية لضمان التخلص من المنظفات \\
\hline 48.0 & 72 & 52.0 & 78 & 16- عدم زيادة الكمية المستخذمة من الكلور في نظافة الملابس أو الدفروشات \\
\hline 84.0 & 126 & 16.0 & 24 & 17- تطيير الغسالة بين حين بإدارتها دورة بالماء والكلور دون وضع غسيل \\
\hline 46.7 & 70 & 53.3 & 80 & 18- تخصيص فوطة لكل فرد \\
\hline 5.3 & 8 & 94.7 & 142 & 19- الدرص على عدم ارتداء أي من الملابس الصوفية على الجسم مباشرة \\
\hline 74.7 & 112 & 25.3 & 38 & 20- الحرص على عدم التغطية بالبطانية على الوجه مبانثرة \\
\hline 90.7 & 136 & 9.3 & 14 & 21- فرش ملاية قطن كعازل بين البطانية والجسم و كذا الوجه \\
\hline 12.0 & 18 & 88.0 & 132 & 22- الحرص على تهوية المفروشات في الثمس بصفة دائمة \\
\hline 0 & 0 & 100 & 150 & 23- غسل البطاطين مع الثنطف و التجفيف الجيد في الثنمس قبل التخزين \\
\hline
\end{tabular}

تشير نتائج الدراسة ( الجدول 3 ) ) إلى أن أكثر الممارسات الخاطئة التي تمارسها أغلبية

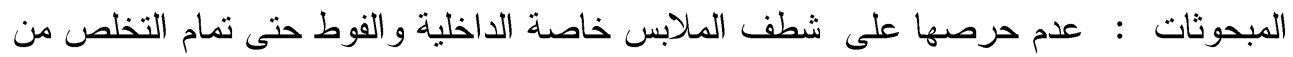
المنظفات ( 100 \% منهن ) ، عدم نقع الملابس الداخلية بعد الثطف لضمان التخلص من المنظفات

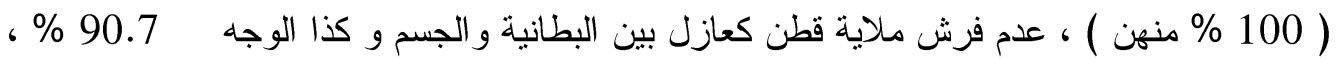

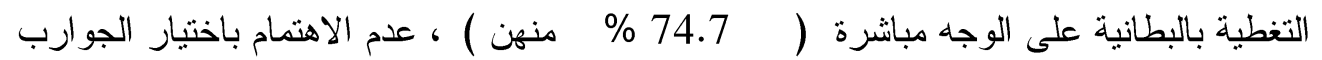


المصنو عة من خامة القطن الخالص وخاصة للأطفال ( 69.3 \% منهن ) ، عدم القيام بنطهير الغسالة بين حين بإدارتها دورة بالماء و الكلور دون وضع غسيل ( 84.0 \% م ) ) ، عدم نقع الملابس الداخلية الملونة قبل الاستخدام ( 60 \% ) ) ، عدم استخدام الماء الساخن في غسيل الملابس الداخلية و المفروشات ( 54.7 \% ) ، عدم غلي الملابس الداخلية بعد غسلها ( 45.3 \% ) م

* ويتصنيف المبحوثات وفقاً لمستوى معارفهن ، ومستوى ممارستهن لبعض البنود المتعلقة بالملابس والمفروشات توضح نتائج البحث ( الجدول 4 ) ) : - انخفاض مستوى المعارف الصحيحة للمبحوثات لبعض البنود المتعلقة لبختيار و استخدام و العناية

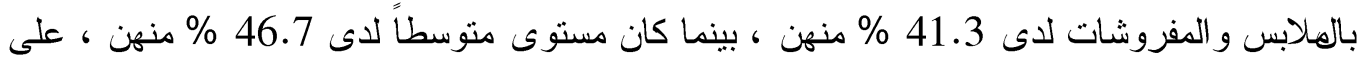
حين كان مرتفعاً لدى 12.0 \% فقط من المبحوثات لـات . - انخفاض مستوى اتباع المبحوثات الممارسات السليمة لبعض البنود المتعلقة لبختيار واستخدام

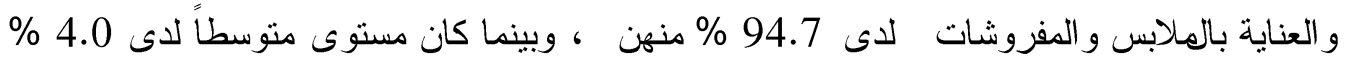
منهن ، ومرتفعاً لدى 1.3 \% فقط من المبحوثات .

جدول ( 4 ) نظنيف المبحوثات وفقاً لمستوى معارفهن ، ومستوى ممارستهن لبعض البنود الهتعلقة بالملابس و المفروشات

\begin{tabular}{|c|c|c|c|c|c|}
\hline$\%$ & 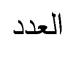 & مستوى اتباع المبحوثات & $\%$ & 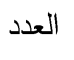 & مستوى معارف المبحوثات لبعض \\
\hline 94.7 & 142 & منخفض ( أقل من 50 \% ) & 41.3 & 62 & منخفض ( أقل من 50 \% ) \\
\hline 100 & 150 & المجموع & 100 & 150 & المجموع \\
\hline
\end{tabular}

: درجة إصابة المبحوثات وأفر اد أسرتهن بأمر اض : العكة الجلدية ، رابع والحساسية التنفسية ، والتهابات العيون :

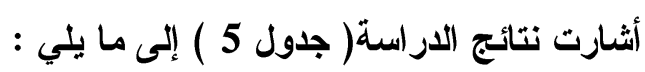

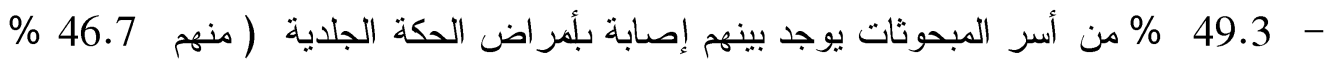
توجد إصابة لفرد واحد من أفراد الأسرة ، 1.3 \% توجد إصابة لفردين أو ثلاثة أفراد من أفراد

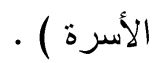

- 30.7 \% من أسر المبحوثات يوجد بينهم إصابة بالحساسية التتفسية (سو اء بالأنف أو الصدر ) (منهر 24.0 \% توجد إصابة لفرد و احد من أفراد الأسرة ، 5.3 \% توجد إصابة لفردين ، و 1.3 \% إصابة لثلاثة أفر اد من أفراد الأسرة) .

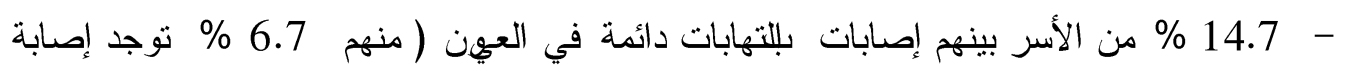
لفرد واحد من أفر اد الأسرة ، 4.0 \% توجد إصابة لفردين أو ثلاثة أفراد من أفراد الأسرة ) . 
جدول ( 5 ) توزيع المبحوثات وفقاً لإصابتهن و أفراد أسرهن ببعض الأمر اض التي قد تتتج عن بسوء الممارسات المتعلقة بالملابس و المفروشات

\begin{tabular}{|c|c|c|c|c|c|c|c|c|}
\hline \multicolumn{6}{|c|}{ عدد الأفر اد المصابة بالأسرة } & \multirow{3}{*}{$\%$} & \multirow{3}{*}{ بالتي بوجد بها الأسر } & \multirow{3}{*}{ 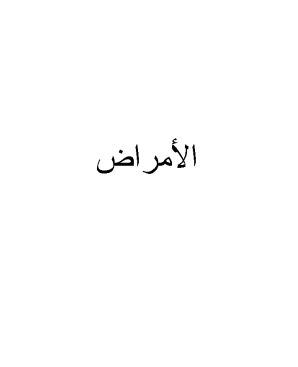 } \\
\hline \multicolumn{2}{|c|}{ تلاث } & \multicolumn{2}{|c|}{ أثثين } & \multicolumn{2}{|c|}{ فرد واحد } & & & \\
\hline$\%$ & 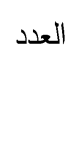 & $\%$ & العدد & $\%$ & العدد & & & \\
\hline 1.3 & 2 & 1.3 & 2 & 46.7 & 70 & 49.3 & 74 & أمر اض الحساسية الجلدية \\
\hline 1.3 & 2 & 5.3 & 8 & 24.0 & 36 & 30.7 & 46 & 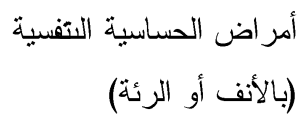 \\
\hline 4.0 & 6 & 4.0 & 6 & 6.7 & 10 & 14.7 & 22 & إلتهابات بالعيون \\
\hline
\end{tabular}

العارة: العلاقات الارتباطية بين متغيرات الاراسة :

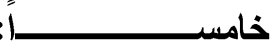

أثثارت نتائج التحليل الإحصائي ( جدول 6 ) إلى العلاقات الارتباطية بين متغيرات الاراسة

- وجود علاقة ارتباطيه عكسية معنوية عند مستوى معنوية 0.01 بين الدرجة الكلية لمجموع الممارسات الصحيحة التي تتبعها المبحوثات لبعض البنود المتعلقة لبختيار واستخدام ونظافة

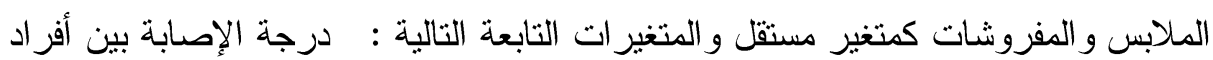
الأسرة بالأمر اض الحساسية الجلدية ( ر = - 0.318 ) ، ودرجة الإصابة بين أفراد الأسرة بالأمر اض الحساسية التنفسية ( ر = - 0.246 ) ، درجة الإصابة بين أفراد

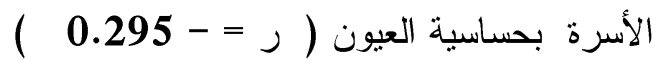

- وجود علاقة ارتباطيه موجبة معنوية عند مستوى معنوية 0.01 بين مجموع المعارف السليمة للمبحوثات لبعض البنود المتعلقة لبختيار و استخدام ونظافة الملابس و المفروشات كمتغير مستقل معله

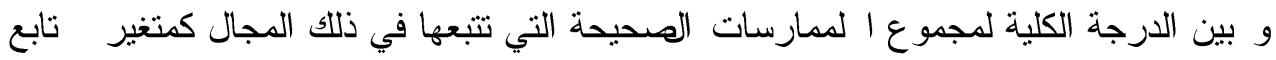

$$
\text { . }(0.339+=\jmath)
$$

- عدم وجود أي علاقة ارتباطيه بين الدرجة الكلية لمجموع ا لممارسات الصحيحة التي تتبعها المبحوثات كمتغير تابع وبين بعض المتغيرات الثخصية و الأسرية للمبحوثات كالعمر و التعليم و عدد الأبناء ونوع الأسرة . 
جدول ( 6 ) العلاقـات الارتبـاطية بين متغيـرات الدر اسة

\begin{tabular}{|c|c|c|c|c|}
\hline \multicolumn{4}{|c|}{ قيمة معاملات الارتباط بين المتغيرات المستقلة و المتغير ات التابعة التالية } & \multirow{6}{*}{ 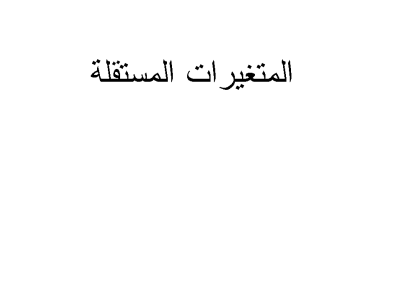 } \\
\hline 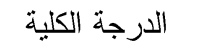 & & & & \\
\hline لمجموع & الإصـابة & الإصابة & 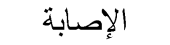 & \\
\hline 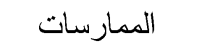 & بحساسية & بالحساسية & بالحساسية & \\
\hline الصحيحة الني & العيون & التتفسية & الجلدية & \\
\hline \multicolumn{4}{|l|}{ تتبعها المبحوثات } & \\
\hline & & & & الدرجة الكلية لمجموع الممارسات \\
\hline 1.000 & $\begin{array}{c}0.295- \\
* *\end{array}$ & $* * 0.246-$ & **0.318 - & الصحيحة التي تتبعها المبحوثات \\
\hline \multirow[t]{2}{*}{$* * 0.339+$} & - & - & - & الدرجة الكلية لمجموع المعارف \\
\hline & & & & الصحيحة للمبحوثات \\
\hline 0.168 & 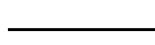 & 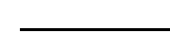 & 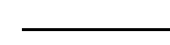 & فئة عمر المبحوثة \\
\hline 0.010 & 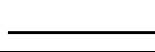 & $\longrightarrow$ & $\longrightarrow$ & فئة تعليم المبحوثة \\
\hline 0.049 & 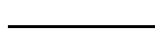 & 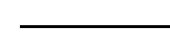 & 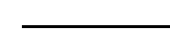 & عدد أبناؤها \\
\hline 0.116 & 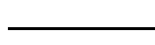 & 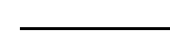 & 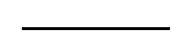 & نوع أسرتها \\
\hline
\end{tabular}

1- العر ادي ، إبر اهيم ( 2004 ) ـ تبادل الملابس في العائلة الواحدة ـ شبكة النبأ المعلوماتية ـ 1 / / http://www.annabaa.org/nbanews/38/110.htm. 2004/ 9 2- لطفي ، سامية إبر اهيم ( 1987 ) ـ در اسة ميدانية للنعرف على بعض الأمر اض الثائعة التي

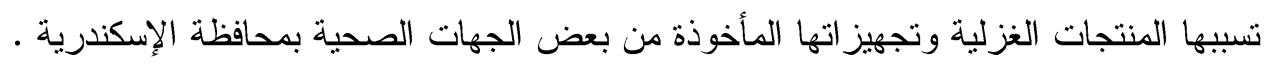

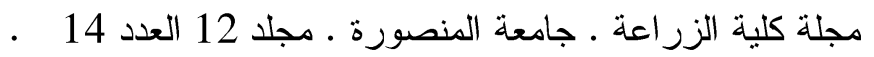
3- لطفي ، سامية إير اهيم ( 2002 ) ـ علم المنسوجات ـ دار القلم ـ الإمارات العربية المتحدة . دبي - (n) 4- الغمغام ، سناء أحمد ( 2002 ) ـ الدليل الذهبي للعناية بالأنسجة ـ وزارة التربية و التعليم . المملكة العربية السعودية . 5- سالم ، فاطمة محمد علي ( 2002 ) ـ دراسة ميدانية لأمر اض الحساسية الجلدية المرتبطة بالمنسوجات و الملابس ومنتجات العناية بها لعينة من المرضى بمدينة الزقازيق ـ مجلة

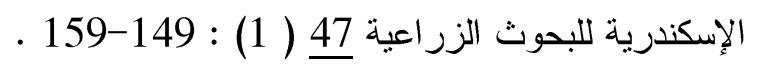

6- حجازي ، محمود ـ مبادئ الأمر اض الجلدية ـ أمر اض الحساسية الموضوعية ـ الباب الباب السادس . كتاب إلكتروني . 7- حجازي ، محمود مبادئ أمر اض الأطفال الجلدية . حساسية الألبسة . الفصل الثاني و العشرون • كتاب إلكتروني . www.dermatologyinfo.net/arabic/ebook_ar.htm

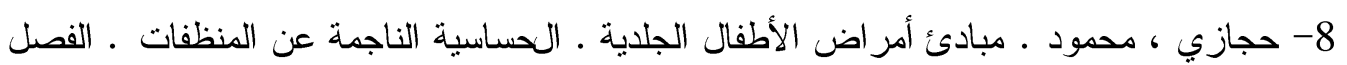
www.dermatologyinfo.net/arabic/ebook_ar.htm . الثالث و العشرون ، كتاب إلكتروني ، 
9 - Allergy UK ( 2012 ). Leading the fight against allergy House Dust Mite . http://www.allergyuk.org/avoiding-respiratory-allergens/house-dust-mite.

10- Edwin K. Joe, M.D .( 2001 ) . Allergic Contact Dermatitis To Textile Dyes . Dermatology Online Journal $\underline{7}$ (1) : 9 .

11- Hatch KL, Maibach HI.( 2000 ). Textile dye allergic contact dermatitis prevalence. Contact Dermatitis $\underline{42}$ (4) :187-195.

12- H H Saudi Research and Marketing . ( 2009 ). Washing-Machine Increase the Risk of Microbes Infection Carrying . www.hh Saudi /com .

13- Khanna M, Sasseville D.( 2001 ) .Occupational contact dermatitis to textile dyes in airline personnel. Am J Contact Dermatitis 12 : 208-210; 2001.

14- Lazarov A, Trattner A, Abraham D, David M . ( 2002 ). Frequency of textile dye and resin sensitization in patients with contact dermatitis in Israel. Contact Dermatitis $\underline{46}: 119$.

15 - Leslie , L. N. ; Marke , N. ; Dallas , M. , J. ; Harger , B. and Miller , J . ( 1990 ) . Dermatological health problems attributed by consumer to contact with textiles . Home Economics Research . Journal, 18 ( 4 ) P : $311-322$.

16- Morris Adrian ( 2012 ). Contact- Dermatitis . Copyright Surrey Allergy Clinic, London http://www.allergy-clinic.co.uk/skin-allergy/contact-dermatitis/.

17 - Westside Dermatology ( Wd ) . ( 2012 ) . Clothing Dye Allergy . Copyright 26 March ,Westside Dermatology // Site by Dapper Walrus http://www.skinallergies.com.au/blog/clothing-dye-allergy . 


\title{
RURAL WOMEN PRACTICES REGARDING CLOTHES AND TEXTILE AND ITS RELATIONSHIP WITH FAMILY MEMBERS ALLERGY AT SOME VILLAGES IN ALEXANDRIA GOVERNORATE
}

\author{
AMAL EL SAYED EL ASAL AND EMAN AWAD SERAG
}

Agricultural Extension \& Rural Development Research Institut - Department of Rural Sociology Research

(Manuscript received 30 December 2012)

\begin{abstract}
- This study aimed at :

- Identifying the knowledge of investigated rural women regarding to choosing, cleaning and using clothes and textile .

- Identifying the practices of investigated rural women regarding to choosing, cleaning and using their cloth and textile.

- Determining the infections degree of family members regarding the skin allergy, respiratory allergy and eyes allergy.

- Determining relationship between whole score of investigated practices with infection of skin allergy, respiratory, and eyes allergy.

- Determining relationship between whole score of investigated practices regarding choosing, cleaning and using their cloth and textile with independent variables like : respondents' knowledge , age, education, number of sons, age and sons education and type of family.
\end{abstract}

- Data were collected by personal interview using questionnaires from 150 rural women at four villages in Agriculture Maamora area in Alexandria governorate.

Correlation coefficient of (Sperman) was used for data analysis.

\section{- The study revealed the following results:}

- knowledge level of $41.3 \% \& 46.7 \%$ of investigated women respectively was low and median regarding some items related to clothes and textile but it was high for $12.0 \%$ from them -- The majority of investigated women ( $97,7 \%)$ their correct practices level regarding some items related to their cloth and textile 
was low and it was median for $4.0 \%$ from them but it was high for only $1.3 \%$ from them .

- $49.3 \%$ of investigated families had infection of skin allergy, $30,7 \%$ of investigated families had respiratory allergy and $17,7 \%$ had eyes infections .

- There was negative significant relationships between investigated practices whole score (as a independent variable) with infection of skin allergy $(r=-0.318)$, respiratory allergy $(r=-0.246)$ and eyes allergy $(r=-0.295)$.

- There was significant Positive relationships between investigated practices whole score (as dependent variable) with some independent variables like : investigated knowledge $(r=0.339)$

- There was no any significant relationships between investigated practices whole score (as dependent variable) with some familial characteristics like : investigated women age, there education numbers of there sons and type of family. 